\title{
Adoção consentida e o Cadastro Nacional de Adoção: harmonização que se impõe
}

\section{Consented Adoption and the National Registry of adoption: harmonization is needed}

Fabíola Albuquerque Lobo*

\section{Resumo}

A lei $n^{0} 12.010 / 09$ trouxe algumas modificações para o procedimento da adoção, a exemplo da proibição de adoção consentida, ou "intuito personae", e da criação do Cadastro Nacional de Adoção, cuja finalidade, entre outras, é desburocratizar o processo de adoção no Brasil e uniformizar todos os bancos de dados existentes, visando possibilitar igualdade de condições a todos os pretendentes cadastrados. Entretanto, o que se observa na realidade é um lado perverso, pois as exigências legais para adoção estão colidindo com os princípios constitucionais de proteção à criança. A fim de superar tal entrave, pretende-se demonstrar a necessária harmonização que se impõe entre as regras do Cadastro e a observância aos princípios da dignidade da pessoa humana, da proteção integral, do melhor interesse da criança, da convivência familiar e da paternidade socioafetiva nos processos de adoção em nosso país.

Palavras-Chave: Constituição Federal. Princípios constitucionais. Direito civil constitucional. Cadastro Nacional de Adoção. Adoção consentida.

\section{Abstract}

The Law on the Adoption Law (12.010 / 09) brought some changes to the adoption of the procedure, the examples of the prohibition of consensual adoption or personae order and the establishment of the National Adoption Register, whose aim among others is less bureaucratic the process adoption

Professora do Departamento de Direito Privado do Centro de Ciências Jurídicas da UFPE. Doutora em Direito Civil pela UFPE. Professora dos Cursos de Mestrado e Doutorado do PPGD/ UFPE. Recife - Pernambuco - Brasil. E-mail: fabiolalobo13@gmail.com 
in Brazil, to standardize all existing databases, aiming at enabling equal basis to all registered applicants. However, what is observed in reality is a dark side, that is, the legal requirements for the child to be adopted are colliding with the constitutional principles of child protection. In order to overcome this obstacle is that it is intended to demonstrate the necessary harmonization necessary between the rules of the Register and the observance of the principles of human dignity, the full protection of the best interests of the child, family life and socioaffective paternity the adoption process in our country.

Keywords: Federal Constitution. Constitutional principles. Constitutional civil law. National Register of Adoption. Agreed adoption.

\section{Introdução}

O presente artigo, como o próprio título indica, tem por finalidade analisar a possibilidade jurídica da adoção consentida, ou "intuito personae", como hipótese, para além das exceções previstas no $\S 13$ do art. 50 do Estatuto da Criança e do Adolescente (ECA), introduzidas pela Lei de Adoção (12.010/09), que prevê apenas três possibilidades de adoção, ainda que realizada por pessoas não cadastradas previamente no Cadastro Nacional de Adoção (CNA).

Não se discute a importância do cadastro, muito menos a finalidade de organizar e garantir igualdade de condições a todos os pretendentes à adoção, mas, por outro lado, não se pode desconsiderar o preceito do art. $5^{\circ}$ da Lei de Introdução às normas do Direito Brasileiro, o qual dispõe que "na aplicação da lei, o juiz atenderá aos fins sociais a que ela se dirige e às exigências do bem comum".

Este é o cerne do problema: de um lado, a imposição legal de observância ao Cadastro; do outro, a mãe ou mesmo os pais biológicos que querem entregar o filho em adoção e escolhem ou direcionam aquela criança para uma pessoa ou família que não esteja previamente cadastrada como pretendentes à adoção. $\mathrm{O}$ que deve prevalecer? A autonomia da vontade da mãe/pais biológicos ou a ordem do cadastro? E na hipótese de vínculo já estabelecido entre os pais socioafetivos e a 
criança, ainda assim deve prevalecer o cadastro, justificando a medida de busca e apreensão da criança para nele incluí-la? É possível, diante da ponderação, no caso concreto, privilegiar o princípio do melhor interesse da criança em detrimento do Cadastro Nacional de Adoção? São essas as questões abordadas no desenvolvimento do trabalho, restando demonstrada a importância prática e a atualidade do tema, pertinente à discussão do modelo de adoção nos moldes do Cadastro Nacional de Adoção.

\section{A doutrina da proteção integral no ordenamento jurídico brasileiro}

A política de proteção especial às crianças tem seu marco inicial com a Declaração de Genebra (1924), mas ganha corpo com a Declaração Universal de Direitos Humanos (1948) e sedimenta-se com a Declaração Universal dos Direitos da Criança (1959).

Do direito à especial proteção para o desenvolvimento físico, mental e social reflete o princípio do interesse superior da criança, com estreita vinculação à proteção dos direitos humanos em geral.

Consoante a Declaração Universal, a criança, em virtude de sua falta de maturidade física e mental, necessita de proteção e cuidados especiais, inclusive da devida proteção legal, tanto antes quanto após seu nascimento; necessita de amor e compreensão para o desenvolvimento pleno e harmonioso de sua personalidade. Sempre que possível, deverá crescer com o amparo e sob a responsabilidade de seus pais, mas, em qualquer caso, em um ambiente de afeto e segurança moral e material em que o interesse superior da criança deverá ser o interesse diretor daqueles que têm a responsabilidade por sua educação e orientação. Tal responsabilidade incumbe, em primeira instância, a seus pais.

No ordenamento jurídico brasileiro, a doutrina da proteção integral, nos moldes dos direitos universalmente garantidos às crianças, radica na Constituição Federal de 1988 (art. 227) e na Convenção Internacional sobre os Direitos da Criança, que, embora tenha sido ratificada pelo 
governo brasileiro em novembro de 1990 (Decreto $n^{\circ}$ 99.710/90), data de 1989. Desse modo, o Estatuto da Criança e do Adolescente (Lei $n^{\circ}$ 8.069/90) tem seu eixo centrado nos princípios da Convenção.

A doutrina da proteção integral representa a estruturação de uma ordem de natureza promocional e a ruptura com o paradigma anterior da criança e adolescente enquanto objeto de direito, e não na condição de titulares de direitos de fundamentais, como passou a se impor.

Tânia Pereira, referindo-se ao art. $3^{\circ}$ da Convenção Internacional sobre os Direitos da Criança, cujo vetor é o princípio do melhor interesse, destaca que "a versão em inglês enfatiza o caráter qualitativo do interesse da criança - the best interest -, enquanto a versão brasileira tem como foco o critério quantitativo - o maior interesse". (PEREIRA, 2005, p. 131). Segundo a autora, o critério qualitativo é a terminologia mais adequada para expressar a doutrina da proteção integral. Daniel O'Donnell, citado por Tânia Pereira (2005, p. 131), afirma que a Convenção ampliou o alcance do princípio. Segundo ele:

o princípio deve inspirar não apenas a legislação, mas todas as medidas concernentes às crianças, tomadas pelas instituições públicas ou privadas de bem-estar social, pelos tribunais, pelas autoridades administrativas. Assim, a vinculação é imediata dos poderes públicos seja do Executivo, Legislativo ou Judiciário, ao princípio do melhor interesse da criança.

Paulo Lobo (2015, p. 69), sobre o significado do princípio do melhor interesse, assim se manifesta:

a criança - incluindo o adolescente, segundo a Convenção Internacional dos Direitos da Criança - deve ter seus interesses tratados com prioridade, pelo Estado, pela sociedade e pela família, tanto na elaboração quanto na aplicação dos direitos que lhe digam respeito, notadamente, nas relações familiares, como pessoa em desenvolvimento e dotada de dignidade. 


\section{0 princípio da convivência familiar}

O Estatuto da Criança e do Adolescente (ECA) alçou o direito à convivência familiar e comunitária no rol dos direitos fundamentais e dispôs no art. 19 que "Toda criança ou adolescente tem direito a ser criado e educado no seio da sua família e, excepcionalmente, em família substituta, assegurada a convivência familiar e comunitária, em ambiente livre da presença de pessoas dependentes de substâncias entorpecentes".

Nessa seara, a Lei n 12.010/2009 (Lei de Adoção) trouxe várias alterações/inclusões ao ECA, visando garantir a plenitude do direito à convivência familiar a todas as crianças e adolescentes. A título de destaque, o $\S$ único do art. 25 inseriu no âmbito da família natural a família extensa ou ampliada como sendo aquela que se estende para além da unidade pais e filhos ou da unidade do casal, formada por parentes próximos com os quais a criança ou adolescente convive e mantém vínculos de afinidade e afetividade.

Após as referências na lei à família natural, destacando que apenas na impossibilidade de permanência na família natural a criança e o adolescente serão colocados sob adoção, tutela ou guarda, observadas as regras e princípios contidos no ECA e na CF/88 (art. $2^{\circ}$ da Lei $n^{\circ}$ 12.010/09), deduz-se que a família substituta é contextualizada numa dimensão excepcional e subsidiária. Tanto que o § 10 do Art. 39 do ECA ratifica que a adoção é medida excepcional.

O princípio da paternidade responsável não pode ser descurado, mas há outros a serem ponderados, a exemplo do princípio do melhor interesse da criança, da afetividade e da convivência familiar.

É majoritária a compreensão, por parte da doutrina especializada e da própria jurisprudência, que uma relação parental se configura para além do critério biológico. São tantas as complexidades e filigranas presentes nas questões envolvendo filiação atualmente que, não por acaso, o reconhecimento jurídico de uma relação parental socioafetiva encontra-se como matéria de repercussão geral no STF. ${ }^{1}$ 
A parentalidade socioafetiva é uma realidade cujo fulcro é uma situação fática consolidada no tempo, e seu reconhecimento jurídico abarca todos os efeitos subjacentes ${ }^{2}$.

Trata-se de conferir à aparência os efeitos da verossimilhança, que o direito considera satisfatória a paternidade socioafetividade é gênero da qual são espécies as paternidades biológica e não biológica. Quer dizer, a afetividade é elemento intrínseco a qualquer espécie de vínculo familiar e presumida nas relações paterno-filiais. (LÔBO, 2004, p. 510).

Nesse mesmo sentido, as considerações de Luiz Edson Fachin (1996, p. 32):

A verdadeira paternidade pode também não se explicar apenas na autoria genética da descendência. Pai também é aquele que se revela no comportamento cotidiano de forma sólida e duradoura, capaz de estreitar os laços da paternidade numa relação psicoafetiva; aquele, enfim, que, além de poder Ihe emprestar seu nome de família, trata-o como sendo verdadeiramente seu filho perante o ambiente social.

Não é um paradoxo priorizar os vínculos com a família biológica em detrimento da família substituta, justamente na lei de adoção e no ECA, que perseguem a máxima efetivação do direito fundamental à convivência familiar? Afinal, com base nos princípios da igualdade, da afetividade e da pluralidade das entidades familiares, a família substituta não pode ser compreendida como uma espécie de segunda classe.

1 BRASIL. STF- Tema 622 - Prevalência da paternidade socioafetiva em detrimento da paternidade biológica. Relator: Min. Luiz Fux. Leading Case: RE 898060). Foi noticiado no site do STF $(24 / 05 / 16)$ que o Min. Fux liberou o referido processo para ser incluído na pauta do Plenário do STF.

2 CC "art. 1593 - O parentesco é natural ou civil, conforme resulte de consangüinidade ou outra origem - $\mathrm{O}$ teor do dispositivo tem dado ensejo doutrinário no sentido de entender que também, a paternidade desbiologizada é capaz de provocar efeitos jurídicos, no caso a socioafetiva." (PEREIRA, 2003, p. 97). Mesmo sentido ver enunciado n 103 da Jornada de Direito Civil $n^{\circ} 01$ do Conselho da Justiça Federal. Ver ainda Welter (2003). 
Os princípios da convivência familiar e da afetividade encontramse intrinsecamente vinculados quanto ao conteúdo. A propósito, em trabalho passado, citando Paulo Lobo (2009, p. 102-103), destacamos a seguinte passagem: "A convivência familiar é a relação afetiva diuturna e duradoura entretecida pelas pessoas que compõem o grupo familiar, em virtude de laços de parentesco ou não, no ambiente comum. [...]".

\section{A política de atendimento à convivência familiar prevista no ECA}

No ECA, encontram-se previstas políticas de atendimento aos direitos da criança e do adolescente, mediante um conjunto articulado de ações governamentais e não governamentais, da União, dos estados, do Distrito Federal e dos municípios (art. 86), nas quais uma das diretrizes volta-se à integração operacional de órgãos do Judiciário, Ministério Público, Defensoria, Conselho Tutelar e encarregados da execução das políticas sociais básicas e de assistência social, para efeito de agilização do atendimento de crianças e adolescentes inseridos em programas de acolhimento familiar ou institucional, com vista à sua rápida reintegração à família de origem ou, se tal solução se mostrar comprovadamente inviável, sua colocação em família substituta, em quaisquer das modalidades previstas no art. 28 dessa Lei (art. 88, VI Redação dada pela Lei n 12.010, de 2009).

A Constituição Brasileira, o Estatuto da Criança e do Adolescente e, posteriormente, a Convenção Relativa à Proteção das Crianças e à Cooperação em Matéria de Adoção Internacional, mais conhecida como Convenção de Haia, de 27 de maio de 1993, assinada e ratificada pelo Brasil, de acordo com o Decreto Federal $n^{\circ} 3.174$ de 16 de setembro de 1999 fomentaram o arcabouço jurídico da política de adoção no Brasil e, em grande medida, a criação das Comissões Estaduais Judiciárias de Adoção- CEJA, no âmbito dos Tribunais de Justiça do país. As Cejas são órgãos articuladores da política de proteção à criança e ao adolescente, promovendo no âmbito estadual respectivo à defesa e garantia do direito à convivência familiar e comunitária e é a Autoridade Central Estadual Brasileira 
que trabalha em sintonia com a Autoridade Central Federal (Secretaria Especial dos Direitos Humanos- Brasília- DF). (RIO DE JANEIRO, 2016, on-line).

Em continuidade às linhas de ação da política de atendimento conjunto à adoção, o Conselho Nacional de Justiça desenvolveu um banco de dados, único e nacional, composto de informações sobre crianças e adolescentes aptos a serem adotados e pretendentes habilitados à adoção, denominado Cadastro Nacional de Adoção (CNA/2008). Importante ressaltar que a criação do Cadastro Nacional é mais uma medida de integração entre as instâncias federativas, de modo que não gera nenhuma incompatibilidade com os outros cadastros (art. 50 caput, $\S 5^{\circ}$ e $\S 8^{\circ}$ do ECA). Entre as finalidades do Cadastro, destacam-se as seguintes:

auxiliar os juízes na condução dos procedimentos de adoção;

desburocratizar o processo de adoção;

uniformizar todos os bancos de dados sobre crianças e adolescentes aptos a adoção no Brasil e pretendentes;

racionalizar os procedimentos de habilitação, pois o pretendente estará apto a adotar em qualquer Comarca ou Estado da Federação, com uma única inscrição feita na Comarca de sua residência;

respeitar o disposto no artigo 31 do ECA, pois ampliam as quatro possibilidades de consulta aos pretendentes brasileiros cadastrados e garante que apenas quando esgotadas as chances de adoção nacional possam as crianças e adolescentes ser encaminhados para adoção internacional;

possibilitar o controle adequado pelas respectivas Corregedorias-Gerais de Justiça;

orientar o planejamento e formulação de políticas públicas voltadas para a população de crianças e adolescentes que esperam pela possibilidade de convivência familiar. (BRASIL. CNJ, 2016, on-line).

Além dessas finalidades do Cadastro, há de se ressaltar algumas medidas previstas no ECA (redação dada pela Lei $n^{0} 12.010 / 2009$ ) que também as robustecessem, quais sejam: 
a) Mesmo diante da manifestação de vontade dos titulares do poder familiar de colocação da criança em família substituta, necessariamente, haverá o encaminhamento às Varas da Justiça da Infância e da Juventude (art.166 ECA), ou seja, a lei retirou dos pais a decisão da entrega direcionada e transferiu para o juiz o procedimento em relação àquela criança (estágio de convivência ou programa de acolhimento).

b) Definir o procedimento para habilitação de pretendentes à adoção (art. 197) e assim garantir a igualdade de condições, mediante a inscrição no cadastro.

O item "b" é aparentemente fácil, mas na prática a lei impõe o cumprimento de oito requisitos para iniciar o procedimento de habilitação dos pretendentes. Após o cumprimento de todas as etapas, o processo é encaminhado ao Ministério Público, para somente depois o juiz deferir ou não a habilitação.

c) A tipificação de crimes e infrações administrativas (arts. 225 ao 258), para evitar qualquer prática de atos ilícitos e/ou possibilidades de negociação.

A Lei de Adoção estabeleceu a necessidade de esgotar todos os meios de manutenção ou reintegração da criança/adolescente na família natural, como medida preferencial em relação a qualquer outra providência. E, em caso de programa de acolhimento institucional, a permanência da criança e do adolescente não se prolongará por mais de dois anos, salvo comprovada necessidade que atenda ao seu superior interesse, devidamente fundamentada pela autoridade judiciária (ECA - art.19 e §).

No relatório de dados estatísticos do CNA (BRASIL. CNJ, 2016, on-line), consta o número de 35.844 pretendentes cadastrados, dos quais $34.469(96,16 \%)$ estão em situação regular no cadastro, e 6.599 crianças/adolescentes cadastrados, dos quais 4.924 (74,62\%) estão disponíveis para adoção. Fazendo uma conta rápida, concluiremos que há sete vezes mais candidatos a pretendentes que o número de 
crianças disponíveis. Então, por que há ainda tantas crianças alijadas do direito fundamental à convivência familiar?

Somos da opinião de que três aspectos concorrem negativamente para a fluidez do processo de adoção. O primeiro deles é a priorização da família biológica, incluindo a família extensa, em detrimento da família socioafetiva. A propósito, a acurada crítica de Paulo Lobo (2015, p. 252), para quem:

condicionar a adoção ao interesse prévio de parentes pode impedir ou limitar a criança de inserir-se em ambiente familiar completo, pois em vez de contar com pai e (ou) mãe adotivos, acolhido pelo desejo e pelo amor, será apenas um parente acolhido por outro, sem constituir relação filial.

O segundo entrave diz respeito aos prazos previstos na lei. E, por fim, o perfil das crianças estabelecido pelos pretendentes, por ocasião da realização do cadastro. Esses dois últimos aspectos estão intrinsecamente relacionados, conforme será demonstrado a seguir.

\section{Um olhar sobre o Cadastro Nacional de Adoção}

Em primeiro plano, vejamos o item "faixa etária" inserto no relatório estatístico de pretendentes (BRASIL. CNJ, 2016, on-line):

Total de pretendentes que aceitam crianças com até um ano de idade:

6462

$18.03 \%$

Total de pretendentes que aceitam crianças com até dois anos de idade:

$6.703 \quad 18.7 \%$

Total de pretendentes que aceitam crianças com até três anos de idade:

$7218 \quad 20,14 \%$

Total de pretendentes que aceitam crianças com até quatro anos de idade:

$5066 \quad 14,13 \%$

Total de pretendentes que aceitam crianças com até cinco anos de idade: 
Os dados apontam que $83,79 \%$ dos pretendentes delimitam em até cinco anos o interesse em adotar. Por conseguinte, as crianças compreendidas na faixa etária dos 6 aos 17 anos (16,21\%) entram na chamada "zona dos inadotáveis", também conhecidas como "crianças invisíveis" ou "filhos do abrigo" (BRASIL. STJ- REsp 1.383.040 - PR. Relator : Ministro Luis Felipe Salomão). Outras variáveis reveladas no relatório também merecem análise, são elas:

Dos 35.844 pretendentes cadastrados, há 8.025 (22.39\%) que somente aceitam crianças da raça branca (assinalando que há também crianças classificadas como da raça negra, amarela, parda e indígena).

Total de pretendentes que desejam adotar somente crianças do sexo feminino: $10.383(28,97 \%)$.

O total de pretendentes que não aceitam adotar irmãos também é bastante significativo, importa no número de 24.884 (69,42\%.), bem como o total de pretendentes que não aceitam adotar gêmeos: 25.806 $(72 \%)$.

d) O número de pretendentes que somente aceitam crianças sem doenças/deficiência (mental/ física), HIV e outros tipos é de 24714 $(68,95 \%)$.

Contrapondo-se os relatórios dos pretendentes com os das crianças/adolescentes, extraímos os seguintes percentuais do Cadastro Nacional de Adoção: 


\section{Pretendentes}

Total CNA

Faixa etária

1 a 5 anos

6 a 17 anos

Raça

Sexo

Grupo de irmãos

Gêmeos

Portadoras de doenças/deficiência tam
$35.844(100 \%)$

$83,79 \%$

$16,21 \%$

$22,39 \%$ somente aceitam crianças de cor branca

$28,97 \%$ somente crianças do sexo feminino

$69,42 \%$ não aceitam

$72 \%$ não aceitam

\section{Crianças/ Adolescentes}

$6.599(100 \%)$

$19,46 \%$

$80,54 \%$

$33,72 \%$ são de crianças brancas.

$48,48 \%$ são crianças de cor parda e as demais negras, amarelas e indígenas.

$44,05 \%$ são do sexo feminino, enquanto $55,95 \%$ são do sexo masculino.

$65,77 \%$ das crianças possuem irmãos

2,41\% são gêmeos

$68,95 \%$ não acei-
$80,62 \%$ não apresentam problemas de saúde

A partir do cruzamento de dados entre os relatórios, percebe-se que as pretensões de quem quer adotar não coincidem com a realidade das crianças cadastradas. Ademais, o excesso de burocracia da lei, a lentidão judicial e o esgotamento das tentativas de manutenção da criança ou adolescente na família natural ou extensa não contribuem para viabilizar a adoção. As exigências legais para que a criança possa ser encaminhada a candidatos e deferida à adoção colidem, como o fator tempo, considerando a preferência dos pretendentes pela faixa etária de 0 a 5 anos. Não por acaso, a faixa etária dos 6 aos 17 tem o maior percentual $(81,58 \%)$ de crianças/adolescentes aguardando, ansiosamente, a remota possibilidade de virem a ser adotados. A respeito, as angustiantes palavras de Maria Berenice Dias (2015, p. 37): 
Enquanto isso a criança fica institucionalizada. Depois de os pais desistirem de ficar com o filho, o Estado sai à caça de algum parente que o queira, até quando se trata de um recém-nascido que ninguém chegou a conhecer. Não vai atrás somente dos familiares com quem a criança mantém vínculos de afinidade e afetividade. Sem atentar a isso, são convocados todos, aos quais é concedida mais de uma chance para dizerem-se desejam ficar com aquela criança. Só depois de todos se negarem a ficar com ela é que será disponibilizada para a adoção. Até que isso ocorra, já se passou muito tempo.

Essa realidade trazida pelo CNA é desumana e impiedosa para a criança. É indiscutível que o procedimento legal para a adoção é uma afronta aos princípios da dignidade da pessoa humana e do melhor interesse da criança. Imaginem quantas crianças/adolescentes poderiam ter suas histórias de vida revertidas com o efetivo direito fundamental à convivência familiar assegurado, segundo a previsão da Lei de Adoção $(12.010 / 09)$ e na forma do Estatuto da Criança e do Adolescente, se a adoção consentida fosse para além das hipóteses previstas na lei, permitindo aos pais biológicos que não desejam ou não podem manter seu filho a possibilidade de eleger o(s) adotante(s).

Sensível ao problema, o Instituto Brasileiro de Direito de Família (IBDFAM), através de enunciados aprovados em Congressos Nacionais, assim se posiciona:

Enunciado 05. Na adoção, o princípio do superior interesse da criança e do adolescente deve prevalecer sobre a família extensa. Enunciado 13. Na hipótese de adoção intuitu personae de criança e de adolescente, os pais biológicos podem eleger os adotantes.

É indiscutível que o CNA tem uma função prestante, reconhecidamente, no âmbito do STJ:

Sem dúvida, a existência de cadastro de adotantes tende a observar o melhor interesse do menor, além de encerrar inúmeras vantagens ao procedimento legal da adoção, na medida em que avalia previamente os pretensos adotantes 
por uma comissão técnica multidisciplinar, minimiza a possibilidade de eventual tráfico de crianças ou mesmo a adoção por intermédio de influências escusas, bem como propicia igualdade de condições àqueles que pretendem adotar. (BRASIL. STJ - REsp 1.262.996 - RN. Relator: Ministro Sidnei Beneti).

Destaco a importância do Cadastro Nacional de Adoção, que coloca a bom termo os diversos interesses que pairam sobre a perfilhação. (BRASIL. STJ - AREsp 256238 - RN. Relator: Ministro Marco Buzzi).

Entretanto, o reconhecimento da relevância do CNA não implica atribuir-lhe caráter absoluto. Sua interpretação deve ser feita em conformidade com os princípios constitucionais, a começar pelos fundamentais princípios da igualdade da filiação (Art. $227 \S 6^{\circ}$ ), do melhor interesse e da igualdade entre as parentalidades socioafetiva e biológica, sem primazia desta sobre aquela.

A opção legislativa de considerar a adoção como medida excepcional e esgotar todas as possibilidades de reinserção com a família biológica $\left(\operatorname{art.~} 39 \S 1^{\circ}\right.$ ) talvez tenha sido para dar maior densidade ao princípio da paternidade responsável, mas na prática fomentou uma colisão entre princípios. Solução que o próprio ordenamento jurídico oferece mediante o critério da ponderação/balanceamento no caso concreto, e não por opção a priori, dada pela lei, a fim de privilegiar a família biológica em detrimento da família socioafetiva, conforme já ressaltado.

Outro dado bastante impactante que ratifica a importância de se repensar o modelo de adoção no Brasil é a redução de $63 \%$ no número de adoções internacionais nos últimos cinco anos: "Em 2010 foram 316 adoções internacionais, número que foi caindo nos anos seguintes chegando a 115 no ano de 2015". Especula-se que a queda decorra dos "gastos com passagem e hospedagem no país durante um mês para o estágio de convivência com a criança.” (BRASIL. CNJ, 2016, on-line). 
Será que a intenção de um pretendente estrangeiro de adotar uma criança/adolescente se mantém diante da exigência legal de cumprir o estágio de convivência durante um mês no Brasil?

\section{0 enfrentamento da controvérsia no STJ}

Em pesquisa realizada no site do STJ (25/05/2016), com o argumento "Cadastro Nacional de Adoção," aparecem 21 decisões monocráticas, das quais nos cingimos à análise apenas daquelas que adentram na temática abordada, ou seja: a concessão ou não de adoção de menor em favor de pessoa não inscrita no Cadastro Nacional de Adoção, principalmente nas hipóteses de vínculo afetivo existente entre as partes.

Em apertada síntese, percebemos, nos julgados analisados, o quanto é polêmico, entre os órgãos julgadores de primeira e segunda instância, a ponderação entre a aplicação estrita e abstrata do Cadastro Nacional de Adoção e a sua flexibilização no caso concreto. Identificamos também certa coincidência dos argumentos utilizados nos pareceres do MP, diante da hipótese de pedido de adoção proposto por pessoa não cadastrada, qual seja: lançar mão do procedimento da busca e apreensão, com o devido acolhimento da criança, ainda que esta conviva e tenha laços afetivos consolidados com os pretensos adotantes, sob os fundamentos de tratar-se de espécie de adoção não autorizada pela lei, de inobservância da ordem de preferência constante no Cadastro Nacional de Adoção, da quebra do princípio da isonomia entre cadastrados e não cadastrados e que esta prática encobriria uma negociação do infante, além de outros interesses escusos que tal situação poderia encobrir, culminando com um parecer conclusivo pela extinção do processo.

Nesse sentido, destacamos um julgado que a sentença não só julgou improcedente o pedido, como extinguiu o processo sem resolução de mérito, sob o fundamento de tratar-se de pedido juridicamente impossível, em virtude de os recorridos não estarem previamente 
registrados no Cadastro Nacional de Adoção, conforme impedimento previsto no artigo 50, § 13, da Lei 8.069/90 (Estatuto da Criança e do Adolescente). Senão vejamos:

Embora a retirada da criança do seio familiar no qual se encontra seja uma medida dura e muitas vezes traumática para a requerente entendo ser necessária para o fiel cumprimento do espírito da nova sistemática que rege a adoção no Brasil, a qual prioriza o Cadastro de Adoção, evitando a intermediação de terceiros na adoção de crianças e buscando o verdadeiro interesse e necessidade dos infantes.

Assim, ante a ausência de inscrição da adotante no Cadastro Nacional de Adoção, não resta alternativa senão acolher o requisitado pelo Órgão Ministerial e extinguir o feito, sem resolução do mérito. (BRASIL. STJ REsp 1.308.689 -RN. Relator: Ministro Luis Felipe Salomão).

Em sede de TJRN, a referida sentença foi reformada nos seguintes termos: "pedido juridicamente possível, conforme jurisprudência pacífica do STJ e tribunais estaduais pátrios, inclusive desta corte. Aplicabilidade do disposto nos artigos 227 da CF/88 e 43 do ECA". ${ }^{3}$

Da análise jurisprudencial ressaltamos ainda outros aspectos, quais sejam:

a) Entendimento do TJ-SC quanto à observância estrita ao cumprimento do CNA, conforme se percebe na transcrição a seguir:

Este Tribunal de Justiça já consolidou o entendimento, respaldado pela Recomendação n.8, de 7-11-2012, da Corregedoria Nacional de Justiça, de que a ordem cronológica dos inscritos no cadastro nacional de adotantes não pode ser afastada, salvo nas hipóteses excepcionais previstas no artigo 50, $\S 13$, do Estatuto da Criança e do

$3 \quad$ AREsp n²20.138- RN e no REsp n 1.289.318-RN, ambas de relatoria do Ministro Marco Buzzi e STJ REsp 1.308.689 -RN. Relator: Ministro Luis Felipe Salomão. 
Adolescente. Assim, não se tratando de adoção unilateral e inexistindo parentesco ou vínculo socioafetivo definitivo entre adotantes e adotados, impõe-se o desprovimento do pedido de adoção formulado por casal não inscrito no cadastro único. ${ }^{4}$

b) Quanto à determinação de transferência de criança para o abrigo, destacamos o processo Resp. 1.383.040, da lavra do Ministro Luis Felipe Salomão, que por sua vez referendou o precedente da Ministra Nancy Andrighi (Segunda Seção, CC 108.442/SC) quando em exame da causa. Assim se manifestou:

O Poder Judiciário, em um ato surpreendente, determina a busca e apreensão de um ser humano, com menos de cem dias de vida, arrancando-o do convívio de amor, carinho e afeição, para jogá-lo em um abrigo de menores, onde, sabemos todos, a esperança nos olhos de tantas crianças, de ter uma família, já nasce morta.

Incumbe, ao Poder Judiciário, com um olhar humano e sensível, defender o lado da esperança na sua expressão mais pura, acenando com a real perspectiva de um futuro mais digno àqueles que estão nascendo sem reais expectativas de consolidação de seus direitos mais básicos.

Na mesma esteira, destacamos as palavras do Ministro Marco Buzzi (AREsp 220138 - RN): "Esta Corte tem entendimento firmado no sentido de que, salvo evidente risco à integridade física ou psíquica do infante, não é de seu melhor interesse o acolhimento institucional ou o acolhimento familiar temporário". ${ }^{5}$

c) Destaque a importância dos princípios. Tal assertiva corrobora com os fundamentos utilizados em alguns julgados, a seguir transcritos:

A observância do cadastro de adotantes vale dizer, a preferência das pessoas cronologicamente cadastradas para adotar determinada criança não é absoluta.

MC n² 21566 - SC. Ministro Raul Araújo.

Ver também precedente (HC 294.729/SP. Rel. Ministro Sidnei Beneti, Terceira Turma). 
Excepciona-se tal regramento, em observância ao princípio do melhor interesse do menor, basilar e norteador de todo o sistema protecionista do menor, na hipótese de existir vínculo afetivo entre a criança e o pretendente à adoção, ainda que este não se encontre sequer cadastrado no referido registro. ${ }^{6}$

a) A matéria relativa à possibilidade de adoção de menores vincula-se obrigatoriamente à necessidade de verificar qual é a melhor solução a ser dada para a proteção dos direitos das crianças, pois são questões indissociáveis entre si. Mister observar sempre a imprescindibilidade da prevalência dos interesses dos menores sobre quaisquer outros, até porque está em jogo o próprio direito de filiação, do qual decorrem as mais diversas conseqüências que refletem por toda a vida de qualquer indivíduo É certo que existem casos excepcionais que autorizam a mitigação da habilitação dos adotantes no competente cadastro para o deferimento do pedido de adoção, possibilitando chamada adoção direta ou intuito personae, o que ocorre quando vislumbrado o melhor interesse da criança. ${ }^{7}$

Por fim, transcrevemos o extrato de uma decisão que, em nosso sentir, sintetiza com exatidão os questionamentos que foram lançados para o desenvolvimento do presente trabalho:

Em verdade, um dos pontos fundamentais da celeuma recai, exatamente, na já mencionada adoção consentida ou intuitu personae.

Nesse passo, o entendimento dominante nos Tribunais do país é o de que não se pode, nem se deve prestigiar a formalidade excessiva que reveste o procedimento previsto pelo legislador, em face do melhor interesse da criança, mais ainda em sendo manifesto o consentimento dos pais biológicos, ou somente de um deles em entregar a criança

6 REsp 1172067- MG. Ministro Massami Uyeda, Terceira Turma. No mesmo sentido REsp 837324/RS. Ministro Humberto Gomes de Barros e AREsp 220.138 - RN. Ministro Marco Buzzi.

7 REsp 1.383.040- PR. Ministro Luis Felipe Salomão. 
à adoção. Esse interesse maior, sim, é que deve prevalecer em todas as circunstâncias, até porque constitucionalmente resguardado (art. 227 CF/88 - princípio da proteção integral à criança).

Ora, aqui vale pontificar que o simples ato de consentir de forma livre e espontânea ${ }^{8}$, ou seja, permitir a entrega da criança/adolescente a quem deseja recebê-la, deve ser visto, nestas hipóteses, como a melhor maneira de mitigar os efeitos, muitas vezes traumáticos e dolorosos, decorrentes do afastamento/retirada da criança da sua família natural para a colocação na substituta. É por essa razão que a regra da nova lei não pode se sobrepuser, quando, diante das peculiaridades que envolvem o caso concreto, haja pleno respeito aos interesses da criança, naquilo que se evidencia, claramente, como o melhor para ela.

Neste aspecto, torna-se evidente o quanto a lei precisa sofrer certa flexibilização, como forma de se alcançar o verdadeiro ideal de justiça.

Não obstante a importância do Cadastro Nacional de Adoção, que coloca a bom termo os diversos interesses que pairam sobre a perfilhação, em casos excepcionalíssimos, é possível que a adoção se dê sem a inscrição dos adotantes no referido rol, tendo em vista o princípio do melhor interesse do menor. ${ }^{9}$

\section{Conclusão}

Demonstrou-se que o Cadastro Nacional de Adoção, apesar da sua importância para os processos de adoção, não constitui um microssistema autônomo; ao contrário, impõe interpretação sistemática e em conformidade com os princípios constitucionais. Não pode ser considerado como uma diretriz absoluta.

\footnotetext{
8 Hipóteses de adoção contida no art. 166 do ECA, que se denomina de adoção consentida ou intuitu personae, na qual os pais biológicos abdicam do pater família e direcionam a criança ou o adolescente a uma pessoa previamente escolhida. AREsp 220138 - RN .Ministro Marco Buzzi.

9 REsp 1.289.318 - RN. Ministro Marco Buzzi.
} 
Principalmente se aceitarmos, a partir da analise dos dados do Cadastro, que o sistema de adoção da maneira como está, corrompido pela burocracia e pelos prazos, inviabiliza para muitas crianças e adolescentes a única possibilidade que lhes restam de estabelecerem vínculos afetivos e de ter uma família para chamar de sua. A adoção é a concretização do direito fundamental à convivência familiar. Por essa razão, é inconcebível uma lei, destituída de sua finalidade social, ser aplicada sem considerar o caso concreto e desprestigiando o princípio do melhor interesse. Inexiste qualquer hierarquia legal entre a família biológica e a socioafetiva, o que demanda interpretação da lei de adoção em harmonia com os princípios fundamentais que tutelam as relações parentais.

Após a análise dos julgados, é possível afirmar que o posicionamento do STJ vem se firmando para flexibilizar a aplicação das regras do CNA, diante de uma relação socioafetiva consolidada, da prevalência do melhor interesse e das reais vantagens para o adotando, conforme preceitua o artigo 43 do ECA. Ratifica-se, assim, a necessária harmonização que se impõe aos casos concretos de adoção intuitu personae e o Cadastro.

A escolha dos pais ou da mãe de entregar seu filho para pessoas ou famílias nas quais confia não configura um ato de rejeição. Paradoxalmente, pode ser um ato de amor, uma tentativa de dar uma vida melhor ao filho, e precisa ser considerado os reais motivos, afastando, claro, quaisquer circunstâncias escusas. Ninguém melhor que os genitores biológicos para escolher a quem pode confiar seu filho para formar relação familiar cercada de afeto.

O direito ao estado de filiação é direito indisponível, portanto, é inconstitucional atribuir exclusividade ao Cadastro Nacional de Adoção, prestigiando o procedimento em detrimento do melhor interesse da criança e da primazia absoluta.

A CF/88, nos mesmos moldes da Declaração Universal dos Direitos do Homem (1948), reconhece a família como base da sociedade, independentemente da origem e do arranjo familiar, como 
lócus privilegiado de realização de cada um dos seus membros. Por extensão, o princípio fundamental da convivência familiar representa "o ninho no qual as pessoas se sentem recíproca e solidariamente acolhidas e protegidas, especialmente as crianças" (LOBO, 2015, p. 68).

\section{Referências}

ALBUQUERQUE, Fabíola Santos. Do direito à convivência familiar e comunitária. In: CAVALCANTI, Francisco Queiroz; BRANDÃO, Cláudio (Org.). Constitucionalização do Direito positivo: teoria hermenêutica e aplicação. Recife: Nossa Livraria, 2009. p.103-123

BRASIL. Conselho Nacional de Justiça. Cadastro Nacional de Adoção. Disponível em:<www.cnj.gov.br> Acesso em: 12 fev. 2016.

BRASIL. Conselho Nacional de Justiça. Guia do Usuário do Cadastro Nacional de Adoção. Disponível em: <www.cnj.gov.br> Acesso em: 12 fev. 2016.

AREsp 220.138 RN. Relator: Min. Marco Buzzi. Disponível em: <www2.stj.jus.br/processo/pesquisa/?src=1.1.3\&aplicaca o=processos.ea\&tipoPesquisa=tipoPesquisaGenerica\&num_ registro=201201761837> Acesso em: 12 fev. 2016.

REsp 1.289.318 RN. Relator: Min. Marco Buzzi. Disponível em:<www2.stj.jus.br/processo/pesquisa/?src=1.1.3\&aplicaca o=processos.ea\&tipoPesquisa=tipoPesquisaGenerica\&num_ registro=201102568430> Acesso em: 12 fev. 2016 .

AREsp 256.238 RN. Relator: Min. Marco Buzzi.

Disponível em:<ww2.stj.jus.br/processo/pesquisa/?src=1.1.3\&apli cacao=processos.ea\&tipoPesquisa=tipoPesquisaGenerica\&num registro=201202401450> Acesso em: 12 fev. 2016 .

REsp 1.383.040 PR. Relator: Min. Luis Felipe Salomão. Disponível em:<ww2.stj.jus.br/processo/pesquisa/?src=1.1.3\&apli cacao=processos.ea\&tipoPesquisa=tipoPesquisaGenerica\&num registro=201301365155> Acesso em: 10 mar. 2016. 
REsp 1.308.689 RN. Relator: Min. Luis Felipe Salomão. Disponível em:<ww2.stj.jus.br/processo/pesquisa/?src=1.1.3\&apli cacao=processos.ea\&tipoPesquisa=tipoPesquisaGenerica\&num registro=201200235401 > Acesso em: 12 fev. 2016 .

HC 294.729 SP. Relator: Min. Sidnei Beneti, Terceira Turma.

Disponível em:< https://ww2.stj.jus.br/processo/revista/documento/ mediado/?componente=MON\&sequencial=35492516\&num_ registro=201401146249> Acesso em: 12 abr. 2016.

REsp 1.262.996 RN. Relator: Min. Sidnei Beneti.

Disponível em:<ww2.stj.jus.br/processo/pesquisa/?src=1.1.3\&apli cacao=processos.ea\&tipoPesquisa=tipoPesquisaGenerica\&num_ registro=201101445617 > Acesso em: 09 mar. 2016.

MC n²1566 SC. Relator: Min. Raul Araújo. Disponível em:<ww2.stj.jus.br/processo/pesquisa/?src=1.1.3\&aplicacao =processos.ea\&tipoPesquisa=tipoPesquisaGenerica\&num_ registro=201303052155. > Acesso em: 12 abr. 2016.

REsp 1.172.067 MG. Relator: Min. Massami Uyeda, Terceira Turma. Disponível em:<ww2.stj.jus.br/processo/revista/ documento $/$ mediado $/$ componente $=$ MON\&sequencial $=6517357 \& \mathrm{n}$ um_registro=200900529624> Acesso em: 16 mar. 2016.

. REsp 837.324 RS. Relator: Min. Humberto Gomes de Barros. Disponível em: < http://migre.me/uNTCg>. Acesso em: 18 fev. 2016.

BRASIL. Supremo Tribunal Federal. Prevalência da paternidade socioafetiva em detrimento da paternidade biológica. Relator: Min. Luiz Fux (Leading Case: RE 898060). Disponível em:<www.stf.jus.br/ portal/jurisprudenciaRepercussao/verAndamentoProcesso.asp?inciden te $=4803092 \&$ numeroProcesso $=898060$ \&classeProcesso $=$ RE\&numeroT ema=622> Acesso em: 16 mar. 2016.

DIAS, Maria Berenice. Adoção como direito preferencial. Revista IBDFAM: Famílias e sucessões, Belo Horizonte, v.12, p. 35-40, nov./ dez. 2015. 
FACHIN, Luiz Edson. Da paternidade: relação biológica e afetiva. Belo Horizonte: Del Rey, 1996.

LOBO, Paulo. Direito civil: famílias. 6. ed. São Paulo: Saraiva, 2015.

. Direito ao estado de filiação e direito à origem genética: uma distinção necessária. In: PEREIRA, Rodrigo da Cunha (Coord.). Afeto, ética, família e o novo Código Civil. Belo Horizonte: Del Rey, 2004. p. 505-530.

PEREIRA, Rodrigo da Cunha. Código civil da família anotado. 2. ed. Porto Alegre: Síntese, 2003.

PEREIRA, Tânia da Silva. Da adoção. In: DIAS, Maria Berenice; PEREIRA, Rodrigo da Cunha (Coord.). Direito de família e o novo código civil. 4. ed. Belo Horizonte: Del Rey, 2005. p. 126-147 RIO DE JANEIRO. Tribunal de Justiça Rio de Janeiro. O papel institucional da Comissão Estadual Judiciária de Adoção. Disponível em: <http://www.tjr.jus.br/institucional/ceja/manifestos/ papeldaceja>. Acesso em: 22 abr. 2016.

Recebido em: 08/03/2016

Aprovado em: 28/05/2016 